\title{
Fungal fucoidanase production by solid-state fermentation in a rotating drum bioreactor using algal biomass as substrate
}

\author{
Rosa M. Rodríguez-Jasso ${ }^{a}$, Solange I. Mussatto ${ }^{a, *}$, Leonardo Sepúlveda ${ }^{b}$, \\ Ana Torrado Agrasar ${ }^{c}$, Lorenzo Pastrana ${ }^{c}$, Cristóbal N. Aguilar ${ }^{b}$, José A. Teixeira ${ }^{a}$ \\ a Institute for Biotechnology and Bioengineering (IBB), Centre of Biological Engineering, University of Minho, Campus de Gualtar, \\ 4710-057 Braga, Portugal \\ b Food Research Department, School of Chemistry, Universidad Autónoma de Coahuila, Unidad Saltillo, Blvd. V. Carranza e Ing. José \\ Cárdenas Valdés, Saltillo, Coahuila, 25001, Mexico \\ c Department of Analytical and Food Chemistry, Food Science and Technology Faculty, University of Vigo, Ourense Campus, 32004 \\ Ourense, Spain
}

\begin{abstract}
A B S T R A C T
Fucoidanase enzymes able to degrade fucoidan were produced by solid-state fermentation (SSF). The fermentation assays were initially carried out in a laboratory-scale rotating drum bioreactor, and two fungal strains (Aspergillus niger PSH and Mucor sp. 3P) and three algal substrates (untreated, autohydrolyzed, and microwave processed seaweed Fucus vesiculosus) were evaluated. Additionally, fermentations were carried out under rotational (10 rpm) and static conditions in order to determine the effect of the agitation on the enzyme production. Agitated experiments showed advantages in the induction of the enzyme when compared to the static ones. The conditions that promoted the maximum fucoidanase activity $\left(3.82 \mathrm{U} \mathrm{L}^{-1}\right)$ consisted in using Mucor sp. 3P as fungal strain, autohydrolyzed alga as substrate, and the rotational system. Such conditions were subsequently used in a 10 times larger scale rotating drum bioreactor. In this step, the effect of controlling the substrate moisture during the enzyme production by SSF was investigated. Moreover, assays combining the algal substrate with an inert support (synthetic fiber) were also carried out. Fermentation of the autohydrolyzed alga with the moisture content maintained at $80 \%$ during the fermentation with Mucor sp. 3P gave the highest enzyme activity $\left(9.62 \mathrm{U} \mathrm{L}^{-1}\right)$.

(c) 2013 The Institution of Chemical Engineers. Published by Elsevier B.V. All rights reserved.

Keywords: Filamentous fungi; Fucoidanase; Fucus vesiculosus; Rotating drum bioreactor; Scale-up; Solid-state fermentation
\end{abstract}

\section{Introduction}

Fucoidans are marine hetero-polysaccharides with a wide spectrum of activity in biological systems. Besides their wellattested anticoagulant and antithrombotic activity, they act on the inflammation and immune systems, have antiproliferative and antiadhesive effect on cells, protect cells from viral infection, and can interfere with mechanisms involved in fertilization (Berteau and Mulloy, 2003; Giordano et al., 2006).
Enzymes with known specificities that catalyze the degradation of fucoidans (fucoidan hydrolase, fucosidase) are important tools for studying the structural peculiarities and the biological role of this class of polysaccharide. Fucoidanase may cleave glycosidic bonds in the core of the polysaccharide, leading to a rapid reduction of the molecular weight (endofucoidanase), or in the edge of the polysaccharide, releasing some oligosaccharides with little decrease of the molecular weight (exo-fucoidanase) (Furukawa et al., 1992). Fucoidanase

Abbreviations: SSF, solid-state fermentation; UA, untreated alga; AA, autohydrolyzed alga; MA, microwave processed alga; NAA, nonisothermal autohydrolyzed alga; SAA, non-isothermal autohydrolyzed alga supported on synthetic fiber cubes.

* Corresponding author. Tel.: +351 253604 424; fax: +351 253604429.

E-mail addresses: solange@deb.uminho.pt, solangemussatto@hotmail.com (S.I. Mussatto).

Received 23 November 2012; Received in revised form 30 January 2013; Accepted 13 February 2013 0960-3085/\$ - see front matter @ 2013 The Institution of Chemical Engineers. Published by Elsevier B.V. All rights reserved. http://dx.doi.org/10.1016/j.fbp.2013.02.004 
enzymes have been found in many invertebrates and marine microorganisms; however most of them exhibit weak titles of activity (Alexeeva et al., 2002; Bakunina et al., 2000; Burtseva et al., 2000). Therefore, there is an interest in establishing a process able to produce this enzyme at elevated levels.

Solid-state fermentation (SSF) is defined as the growth of microorganisms on a solid matrix with low content of free water. SSF has been widely studied in recent years because this bioprocess is considered an economical technology with potential to successfully convert inexpensive agro-industrial wastes, as well as plant substrates, in a large variety of valuable compounds (Aguilar et al., 2008; Martins et al., 2011; Singhania et al., 2009). When compared to the liquid media used in submerged fermentation systems, the solid media used in SSF contain less water, but they present an important gas phase between the particles (Durand, 2003). This condition favors the development of filamentous fungi, which have great capacity to colonize the interparticle spaces of solid matrices. Different bioreactors working under agitated or static conditions have been used in SSF processes. The agitated systems comprise rotating drums, gas-solid fluidized beds, rocking drums, horizontal paddle mixer, etc.; while the static ones include packed-bed and trays bioreactors (Durand, 2003).

The present study evaluated the production of fucoidan hydrolytic enzymes by fungal strains through SSF in a rotating drum bioreactor. Different algal biomasses were used as substrate (untreated, autohydrolyzed, and microwave processed) in order to verify the effect of the substrate pretreatment on the enzyme production. Additionally, two different fungal strains were also used in the experiments, which were demonstrated in a previous study as having great potential for fucoidanase production (Rodriguez-Jasso et al., 2010). Assays were performed in laboratory-scale in order to evaluate the influence of the fungal strain, the algae pre-treatment, and the agitation of the system on the enzyme production. The scale-up of this system on the enzyme production was also investigated and is discussed.

\section{Materials and methods}

\subsection{Microorganisms and inocula}

Aspergillus niger PSH and Mucor sp. 3P strains belonging to the DIA/UAdeC fungal collection (Food Research Department/University of Coahuila, Mexico), conserved under cryopreservation conditions $\left(-80^{\circ} \mathrm{C}\right)$ were used in this study. Potato dextrose agar (PDA-Difco) plates were used for the spores' propagation at $27^{\circ} \mathrm{C}$. To be inoculated in the fermentation media, spores from 7 days cultures were collected in $0.1 \%(\mathrm{w} / \mathrm{v})$ Tween 80 solution and counted in a Neubauer chamber.

\subsection{Raw material and pre-treatment conditions}

Autohydrolyzed and microwave processed algal biomass from Fucus vesiculosus species (collected from Praia Norte, Viana do Castelo, Portugal, during spring 2011), were evaluated as substrate in the SSF experiments. Untreated alga was also tested as a control assay. The conditions used for microwave and autohydrolysis pre-treatment were based on previously obtained results (Rodriguez-Jasso et al., 2011, 2013).

Microwave-assisted extraction was performed in a digestion oven model MDS-2000 (CEM Corporation, Matthews, NC). For the extraction reaction, milled seaweed was suspended in distilled water to obtain an alga/water ratio of $1 / 25(\mathrm{w} / \mathrm{v})$. The suspension was placed into the extraction vessel and was irradiated at $172^{\circ} \mathrm{C}$ for $1 \mathrm{~min}$, being subsequently cooled in ice bath. Then, the produced hydrolysate was separated from the residual alga material by filtration through nylon fiber.

For the autohydrolysis process, milled seaweed was suspended in distilled water to obtain an alga/water ratio of $1 / 25$ $(w / v)$ and the mixture was placed in a stainless steel cylinder reactor that was submerged in a silicon oil bath (Julabo Labortechnik $\mathrm{GmbH}$, Seelbach, Germany). The autohydrolysis process was carried out at $180^{\circ} \mathrm{C}$ for $20 \mathrm{~min}$. At the end of the reaction, the reactors were immediately cooled in an ice bath and the produced hydrolysate was separated from the residual alga material by vacuum filtration.

\subsection{Invasion capacity of fungal strains}

Fungal growth was evaluated in Petri dishes. For the experiments, untreated alga (UA), autohydrolyzed alga (AA) and microwave processed alga (MA) biomass were used as sole carbon source, and their moisture content was adjusted to $80 \%$ by addition of Czapek Dox modified medium composed of $\left(\mathrm{gL}^{-1}\right)$ : urea (5.0), $\mathrm{KH}_{2} \mathrm{PO}_{4}$ (1.5), $\mathrm{KCl}(0.5), \mathrm{MgSO}_{4}$ (0.5), and hunter traces (0.1) (pH 5.0) (Hill and Kafer, 2001). Each strain was inoculated by puncture in the center of $60-\mathrm{mm}$ Petri dishes with a suspension containing $1 \times 10^{7}$ spores $\mathrm{mL}^{-1}$. Radial growth was monitored kinetically, every $4 \mathrm{~h}$ during the day and $8 \mathrm{~h}$ during the night, using a digital micrometer (Mitutoyo 293-561, Japan) (Rodriguez-Jasso et al., 2010). The growth curves data corresponding to the exponential phase were analyzed by linear and exponential regressions to estimate the radial growth rate $\left(U_{r}, \mathrm{~mm} \mathrm{~h}^{-1}\right)$ (Loera and Viniegra-González, 1998; Vonshak and Maske, 1982).

A scanning electron microscope (Nova NanoSEM 200, Netherlands) was used to visualize the mycelia growth on the different algal substrates. For the analyses, the samples were fixed on a specimen holder and then coated with gold under high vacuum condition.

\subsection{Rotating drum bioreactor and fermentation conditions}

The rotating drum bioreactor used in this study consisted of a horizontal module with six independent acrylic columns ( $36 \mathrm{~cm}$ height $\times 6 \mathrm{~cm}$ diameter), each one connected to a $10 \mathrm{rpm}$ motor (Fig. 1A). For the laboratory-scale experiments, each column supported three 50 -mL syringes that contained the solid substrate (Fig. 1B). In these assays, two fungal strains (A. niger PSH and Mucor sp. 3P) and three algal biomass (UA, $\mathrm{AA}$, and $\mathrm{MA}$ ) were used, and the processes were carried out under static or agitated $(10 \mathrm{rpm})$ conditions. Before the SSF experiments, the algal biomass was dried at $35^{\circ} \mathrm{C}$ and sterilized at $100^{\circ} \mathrm{C}$ during $60 \mathrm{~min}$. Each syringe was filled with $4 \mathrm{~g}$ of solid substrate pre-inoculated with $1 \times 10^{7}$ spores $^{-1}$ of support, moistened with Czapek Dox modified media $(\mathrm{pH}$ 5.0) to achieve $80 \%$ moisture content. The system was incubated at $30^{\circ} \mathrm{C}$ during $96 \mathrm{~h}$. Samples were withdrawn every $12 \mathrm{~h}$ and filtered through nylon membrane in order to recover the fermentation broth. All the experiments were carried out in triplicate. 

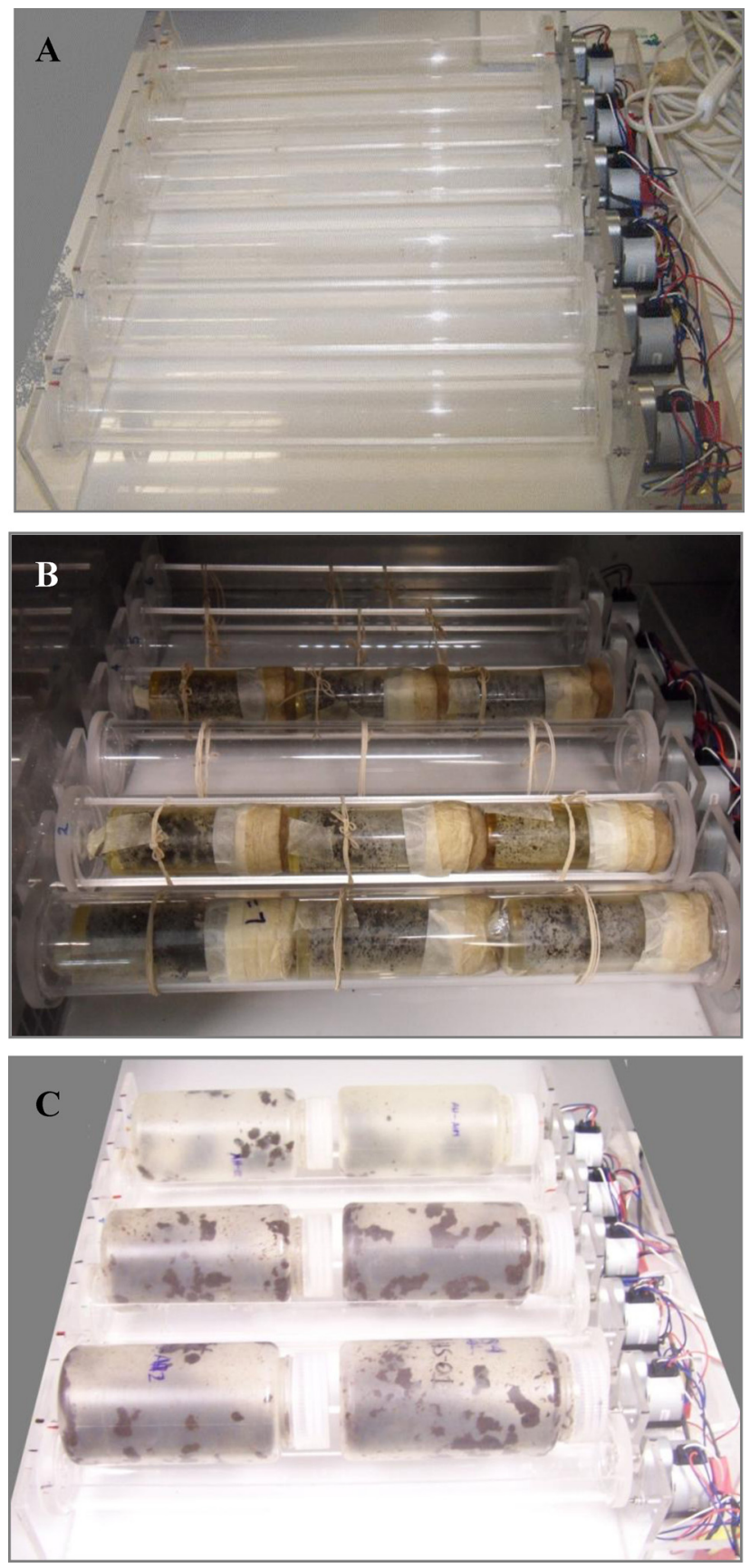

Fig. 1 - Rotating drum bioreactor: (A) serial column module; (B) module with $50 \mathrm{~mL}$-syringes; and (C) module with 500 mL-flasks.

\subsection{Fermentation conditions for the scale-up experiments}

Autohydrolyzed algal biomass for the scale-up experiments was produced in an 18-L total volume stainless steel reactor (Parr Instruments Co.). Pre-treatment was carried out at $160^{\circ} \mathrm{C}$ in non-isothermal profile, at $120 \mathrm{rpm}$. At the end of the treatment, the solid phase was separated by filtration and the recovered solids were washed with distilled water. The excess of water in non-isothermal algal biomass (NAA) was eliminated by centrifugation and the moisture content was quantified. The autohydrolysis liquor was filtered and stored at $4{ }^{\circ} \mathrm{C}$.

In this step of the study, the effect of the type of substrate and culture media used to moisten it, on fucoidanase production was evaluated. Three different algal biomass were used: (a) untreated alga (UA), (b) non-isothermal autohydrolyzed alga (NAA) and (c) non-isothermal autohydrolyzed alga supported on synthetic fiber cubes (Green Heavy Duty Scour Pad-Scotch Brite ${ }^{\mathrm{TM}}, 3 \mathrm{M}$ Company, Spain, $4 \mathrm{~mm} \times 4 \mathrm{~mm}$ ) (SAA). The moisture content of the solid substrates was maintained at $80 \%$ during SSF experiments by adding water or autohydrolysis liquor to algal biomass. Culture media were also supplemented with Czapek Dox salts at the same proportions mentioned in the previous section.

SSF assays were carried out in a rotating drum bioreactor with 500-mL flasks (Fig. 1C). Each flask contained $50 \mathrm{~g}$ of wet substrate $(70 \%)$ inoculated with spores of Mucor sp. 3P $\left(1 \times 10^{7}\right.$ spores $~^{-1}$ dry support). Moisture content was then adjusted to $80 \%$ with Czapek Dox salts. Experiments with SAA also contained $10 \mathrm{~g}$ of synthetic fiber cubes, which were previously washed by boiling in distilled water for $30 \mathrm{~min}$ and then drying overnight at $60^{\circ} \mathrm{C}$ (Mussatto et al., 2009). These fermentation systems were maintained at $30^{\circ} \mathrm{C}$ during $120 \mathrm{~h}$. All the experiments were carried out in duplicate.

\subsection{Analytical methods}

The moisture content of the fermented solids samples $(0.5 \mathrm{~g})$ was determined in accordance with the AOAC method. The sample was dried at $103 \pm 2{ }^{\circ} \mathrm{C}$ for $2 \mathrm{~h}$, cooled in a desiccator and reweighed. The total sugar content in algae hydrolyzed samples and in the fermented broth obtained after SSF was estimated by the anthrone method (Ludwig and Goldberg, 1956) using glucose as standard. This value was used to determine the percentage of substrate consumption. Protein was estimated by the Bradford assay.

Fucoidanase activity was determined by measuring the amount of reducing sugars (Miller, 1959) produced from fucoidan through the following reaction: $900 \mu \mathrm{L}$ of substrate (1\% fucoidan from Laminaria japonica dissolved with $200 \mathrm{mM}$ acetate buffer, $\mathrm{pH} 4.5$ ) was mixed with $100 \mu \mathrm{L}$ of enzyme extract, and the mixture was maintained at $37^{\circ} \mathrm{C}$ for $24 \mathrm{~h}$. One unity (U) of fucoidanase activity was defined as the amount of enzyme able to release $1 \mu \mathrm{mol}$ of reducing sugars per hour under the assay conditions. Inactivated enzyme solution was used as blank.

Fucosidase activity was estimated through the following reaction: a substrate solution containing $50 \mu \mathrm{L}$ of $\rho$-nitrophenyl- $\alpha$-L-fucoside $5 \mathrm{mM}$ dissolved with $90 \mu \mathrm{L}$ of $200 \mathrm{mM}$ acetate buffer $\mathrm{pH} 4.5$ was mixed with $10 \mu \mathrm{L}$ of enzyme extract, and the reaction was maintained at $37^{\circ} \mathrm{C}$ for $1 \mathrm{~h}$. One unit (U) of fucosidase activity was defined as the amount of enzyme able to release $1 \mu \mathrm{mol}$ of $\rho$-nitrophenyl per hour under the assay conditions.

\section{Results and discussion}

SSF has been widely studied as an inexpensive and potential process to produce enzymes. In the present study, two fungal strains and three algal substrates were used in the SSF experiments for the production of fucoidan degrading enzyme. Such variables were chosen based on previous studies (RodriguezJasso et al., 2010, 2013), where A. niger PSH and Mucor sp. 3P were selected among several strains as the fungi with the highest titles of enzymatic activity; and the algal substrates were chosen based on their high quantity of fucoidan, as a natural inducer source for fucoidanase production. Fig. 1 shows the fungi cultivation in the syringes used on the rotating drum bioreactor. After 5 days of fermentation it was possible to 


\begin{tabular}{|c|c|c|}
\hline Substrate & Fungal strain & $\begin{array}{c}\text { Radial growth rate } \\
U_{r}\left(\mathrm{~mm} \mathrm{~h}^{-1}\right)\end{array}$ \\
\hline \multirow[t]{2}{*}{ Untreated alga - UA } & Aspergillus niger PSH & $0.11 \pm 0.02$ \\
\hline & Mucor sp. 3P & $0.20 \pm 0.00$ \\
\hline \multirow{2}{*}{$\begin{array}{l}\text { Microwave processed } \\
\text { alga - MA }\end{array}$} & Aspergillus niger PSH & $0.34 \pm 0.01$ \\
\hline & Mucor sp. 3P & $0.40 \pm 0.03$ \\
\hline \multirow{2}{*}{$\begin{array}{l}\text { Autohydrolyzed alga - } \\
\text { AA }\end{array}$} & Aspergillus niger PSH & $0.37 \pm 0.01$ \\
\hline & Mucor sp. 3P & $0.46 \pm 0.02$ \\
\hline
\end{tabular}

visualize the formation of mycelia covering most of the substrate surface.

\subsection{Effect of algal substrate on fungal growth}

The two fungal strains used in the present study (A. niger PSH and Mucor sp. 3P) have been widely used in biotransformations of antimicrobial molecules from different vegetal materials, including pomegranate husk and coffee silverskin (Machado et al., 2012; Robledo et al., 2008). Based on the promising results that they have presented, such fungi were chosen to be used in the present study. The capacity of these two strains to invade the three algal substrates (UA, AA and MA) here evaluated was verified in an initial stage. The determination of the radial growth rate allowed identifying the microorganism with higher adaptation to the media selected for fucoidanase production. As can be seen in Table 1, both the strains showed mycelia growth on the different algal substrates. The highest radial growth rates were observed with Mucor sp. 3P independently of the substrate used. When comparing the different substrates, the lowest fungal invasion was observed in the untreated alga (UA), while the highest radial growth rates were provided by the AA.

Scanning electron micrographs of the algal biomasses revealed higher roughness and porosity in MA and AA than in UA, which probably promoted a better micro-environment for the microorganism invasion. Fig. 2A shows that a few quantity of mycelium was present in the surface of UA, when compared to the huge amount of hyphae and spores observed in the surface of the pretreated algae (Fig. 2B and C).

\subsection{SSF in laboratory-scale rotating drum bioreactor}

\subsubsection{Effect of moisture content on SSF}

The moisture is a variable of great importance in SSF since it strongly affects the microbial growth, metabolic reactions, and mass transfer processes (Marin-Cervantes et al., 2008; Mussatto et al., 2012). The moisture of the SSF systems evaluated in the first part of this study (using different algal substrates and fungal strains, under agitated or static conditions) was verified at the end of the fermentations. According to the results, the substrates under static condition presented little variation in the moisture content $(\leq 5 \%)$ during the fermentation, except MA inoculated with Mucor sp. 3P that presented moisture drop of $15 \%$. On the other hand, the assays under rotational conditions showed more significant moisture lost $(<10 \%)$, and for both fungal strains, experiments with AA presented the highest moisture drop (14\% and 11\% for Mucor sp. 3P and A. niger PSH, respectively).

The mixture in SSF bioreactors is associated with a better aeration of the medium, and is able to create, as a
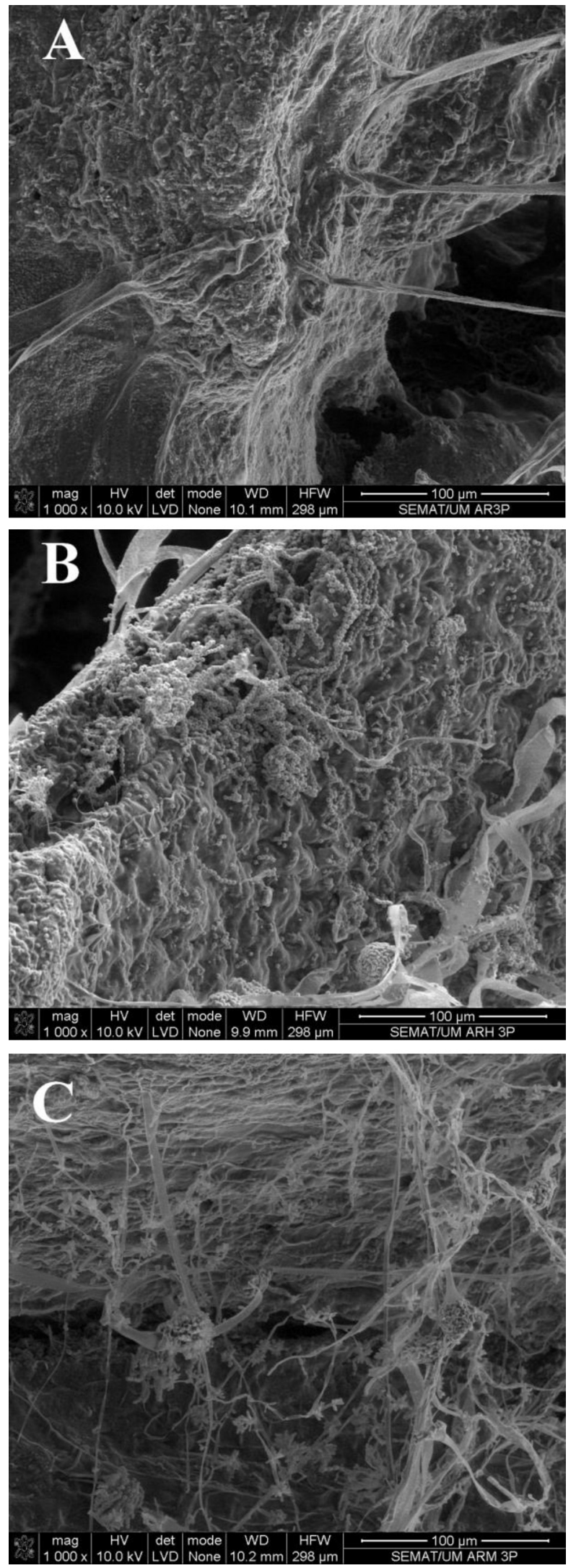

Fig. 2 - Scanning electron micrographs of Mucor sp. 3P fungal invasion on algal substrates after $48 \mathrm{~h}$ of cultivation: (A) untreated alga; (B) autohydrolyzed alga; and (C) microwave processed alga. Magnification: 1000 -fold. 

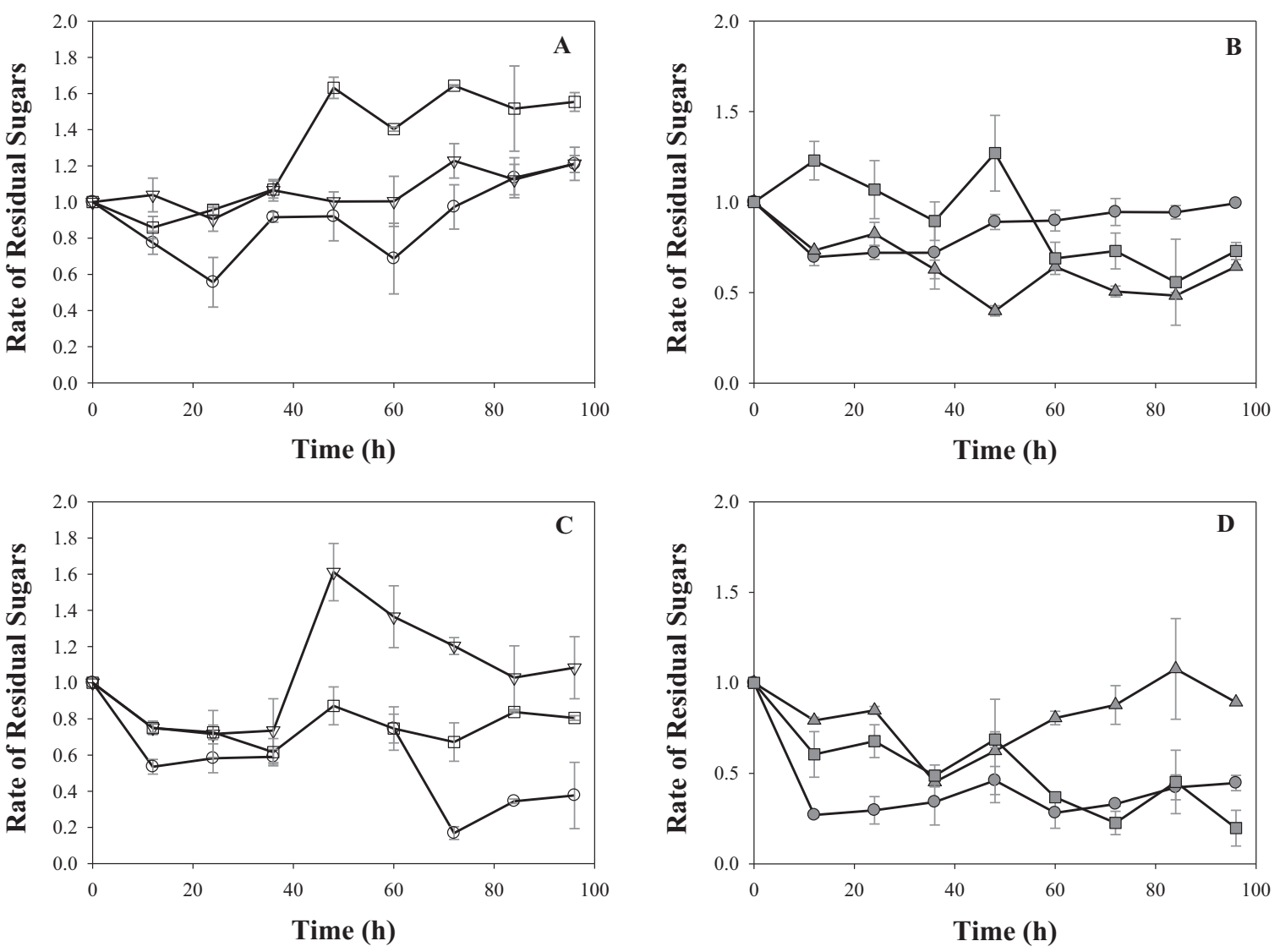

Fig. 3 - Profiles of hydrolyzed sugars accumulated in the fermentation broth, which were recovered from algal substrates during the fungal cultivation period. Static (A and B) and rotational (C and D) conditions. Aspergillus niger PSH: $(O)$ untreated alga (UA); $(\nabla)$ autohydrolyzed alga (AA); $\square$ ) microwave processed alga (MA); Mucor sp. 3P: (Ө) untreated alga (UA); ( $($ ) autohydrolyzed alga (AA); (口) microwave processed alga (MA).

consequence, an ambient more suitable for the microbial growth. However this phenomenon has been reported to cause a decrease of substrate free water content during the process (Marin-Cervantes et al., 2008; Mussatto et al., 2012). The moisture lost is also caused by the metabolic heat rising from microbial respiration, as a result of the microorganism growth (Hamidi-Esfahani et al., 2004).

In the present study, although SSF using AA presented the highest moisture drop, the final moisture of this system was in the range considered suitable for the microorganism development. In general, moisture of the substrates in SSF systems must oscillate between 30 and $85 \%$. Low values might induce the sporulation of the microorganism, while more elevated levels may reduce the porosity of the system, producing oxygen transfer limitation (Mussatto et al., 2012).

\subsubsection{Effect of substrate on sugars consumption during SSF}

The quantity of total sugars solubilized from the different algal substrates during the SSF in the rotating drum bioreactor was quantified in the fermentation broths. Fig. 3A-D shows the profiles of sugars consumption during the cultivation period, which was calculated taking into account the sugars solubilized in the fermentation broth and the sugars present in the hydrolyzed substrate to each fermentation time. Under static conditions, cultures with A. niger PSH (Fig. 3A) presented, in all the algal substrates, a little decrease in the total sugars content before the initial $24 \mathrm{~h}$ of fermentation, followed by a continuous accumulation until the end of fermentation. For Mucor sp. 3P (Fig. 3B) this behavior was only observed for UA; the algal substrates AA and MA showed a hydrolyzed sugars consumption of $48 \%$ and $55 \%$, respectively, reached within 48-60 h.

The effect of the rotational agitation on sugars consumption was more efficient in cultures of Mucor sp. 3P than in A. niger PSH cultures (Fig. 3C and D). For Mucor sp. 3P (Fig. 3D) a constant decrease was observed in the profile for MA substrate, achieving a sugar consumption percentage of $80 \%$; while for AA substrate the sugars consumption was faster during the first $36 \mathrm{~h}(54 \%)$, after that a possible lack of assimilation of the hydrolyzed products by the microorganism caused the increase of sugars concentration.

The differences observed in these experiments can be explained by the wide variety of sugars in the composition of the studied algae, which include fucoidan, laminaran, alginate and agar as the main carbohydrates. In addition, different filamentous fungi have different potential to adapt to complex and recalcitrant substrates, such as the brown algae; and their morphology is closely linked to the properties of the obtained fermentative broth (Grimm et al., 2004).

\subsubsection{Production of fucoidan-degrading enzymes by SSF}

SSF experiments using filamentous fungi were carried out with the purpose of producing enzymes with fucoidanolytic activity in the presence of natural inductors present in brown algae (fucoidan, laminaran, alginate and agar). The enzymatic activity was quantitatively detected by monitoring the release of fucoidan oligosaccharides by conventional reducing assay. Fucoidan hydrolytic enzymes were only analyzed as extracellular metabolites in the culture supernatant, since some 


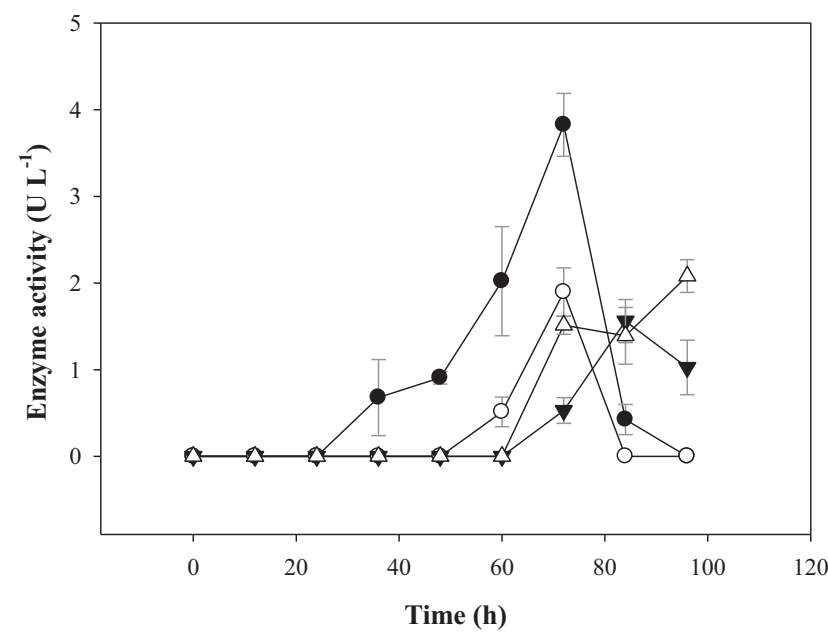

Fig. 4 - Fucoidanase production by Aspergillus niger PSH and Mucor sp. 3P cultivated in algal substrates in the laboratory-scale rotating drum bioreactor. A. niger PSH: (O) microwave processed alga (10 rpm). Mucor sp. 3P: (Ө) autohydrolyzed alga $(10 \mathrm{rpm}) ;(\mathrm{v})$ microwave processed alga (10 rpm); ( $\Delta$ ) microwave processed alga (static).

studies have reported insignificant presence of intracellular fucoidanolytic activity (Descamps et al., 2006; Rodriguez-Jasso et al., 2010).

The fungal cultures that expressed fucoidanase activity through the fermentation time are shown in Fig. 4. Mucor sp. 3P showed better ability to secrete enzymes able to degrade fucan polysaccharide structures than A. niger PSH, since three cultures of this strain presented enzymatic activity while only one culture of A. niger PSH showed enzyme production. None of the fungal strains produced fucoidan hydrolyzing enzymes from UA. Static fermentations have also not favored the enzyme production, which only occurred when using MA as substrate for Mucor sp. 3P cultivation. The maximum titles of fucoidanolytic activity were achieved after $72 \mathrm{~h}$ of cultivation; the best value $\left(3.82 \mathrm{UL}^{-1} ; 0.37 \mathrm{U} \mathrm{mg}^{-1}\right.$ protein) was obtained with Mucor sp. 3P grown on AA substrate under agitation. The other cultures that showed enzymatic activity $\left(1.56-2.08 \mathrm{U} \mathrm{L}^{-1}\right)$ were grown on microwave-processed alga (MA). With exception of the experiment using MA substrate under static condition, the other assays presented lost of enzyme activity after reaching the maximum value. Such behavior could be related to the sugars accumulation to the culture media, as discussed before. According to Descamps et al. (2006) since extracellular enzymes can degrade sulfated fucoidans from algae, it is thus likely that the microorganism attacks the fucoidan structure by cleaving linkages within blocks of alternating $\alpha-1 \rightarrow 3$ and $\alpha-1 \rightarrow 4$ L-sulfated fucose residues.

It is worth noting that the enzyme production by Mucor sp. 3P grown on MA substrate under agitation was lower than that using AA substrate under agitation. This result suggests an important influence of the nature of the substrate on enzyme formation. However, the effect of the nature of the substrate was strongly affected by the system used, i.e., AA was better than MA under agitation conditions, but it was worse than MA under static conditions. Therefore, both variables can be considered as having great influence on the production of fucoidan degrading enzymes.

As a whole, the results obtained in the current study can be well compared to other results reported in the literature for fucoidanase production. Ivanova et al. (2002) and Alexeeva et al. (2002) reported titles of $0.4 \mathrm{UL}^{-1}$ and $0.49 \mathrm{U} \mathrm{mg}^{-1}$ protein, respectively, with Pseudoalteromonas $s p$. using only fucoidan as substrate. Burtseva et al. $(2000,2003)$ isolated enzymes with fucoidan hydrolase activity from 33 species of marine invertebrates, and obtained activities between 0.20 and $0.26 \mathrm{U} \mathrm{mg}^{-1}$ protein.

\subsection{Scale-up of the rotating drum bioreactor for fucoidanase production by SSF}

The conditions that gave the maximum enzyme activity in the laboratory-scale rotating drum bioreactor (Mucor sp. 3P as fungal strain, and AA as substrate) were used in this scaleup study, which employed cylinders of $500 \mathrm{~mL}$ total volume instead of the $50-\mathrm{mL}$ syringes. In this case, the autohydrolysis pre-treatment of $F$. vesiculosus alga, which was previously carried out in an isothermal profile at $180^{\circ} \mathrm{C}$ for $20 \mathrm{~min}$; was modified to non-isothermal profile at $160^{\circ} \mathrm{C}$, in order to maintain the same severity effect over algae fibers. For comparison, assays using the untreated alga, as well as the pretreated alga mixed with an inert support material (synthetic fibers) were also performed.

The moisture content of the substrates used in the SSF scale-up assays was maintained constant throughout the fermentation time by addition of water or the autohydrolysis liquor. However, fucoidanase activity was only observed when the substrates were moistened with water. No fucoidanase activity was obtained when using the autohydrolysis liquor, which could be related to enzyme-substrate inhibition by other sugars present in the liquor after the autohydrolysis reaction. It is worth mentioning that sugars degradation compounds (furfural and hydroxymethyl furfural) that are compounds inhibitory for the microbial metabolism (Mussatto and Roberto, 2004) were not detected in the liquor (data not shown).

For the different substrates, the secretion of fungal enzyme showed similar performance along the fermentation time, reaching the highest titles after $72 \mathrm{~h}$ (Fig. 5A). The maximum activity $\left(9.62 \mathrm{UL}^{-1}\right)$ was obtained when using the non-isothermal algal biomass (NAA); but similar to the small scale experiments, the enzyme production fall down after attaining the maximum value (in this case, until six units in the subsequent $48 \mathrm{~h}$ ), which could be associated to the increase in the concentration of sugars hydrolyzed to the media (Fig. 5B). On the other hand, although the maximum title obtained in the experiment with the combination of algal substrate and synthetic fiber (SAA) was only $6.19 \mathrm{UL}^{-1}$ ( 3 units lower than with NAA), a stable production was observed in this case until $120 \mathrm{~h}$ of fermentation. Additionally, no accumulation peak was observed in the total sugars consumption. In fact, inert supports have been reported to improve some of the disadvantages of SSF substrates, such as excessive thickness, low porosity and inefficient nutrient uptake (Marin-Cervantes et al., 2008).

Finally, the induction of $\alpha$-L-fucosidase in the scale-up experiments was also evaluated. As well as the fucoidanases, $\alpha$-L-fucosidase is also an enzyme with ability to hydrolyze fucoidan. However, this enzyme cleaves L-glucosyl linkages at non-reducing terminal, while fucoidanases have two types of cleavage pattern, one is an endo-cutter that produces oligomers; and the other type is an exo-cutter that results in monomers (Holtkamp et al., 2009; Wu et al., 2011). All the cultures of Mucor $s p$. 3P showed specificity over the 
Table 2 - Fucosidase activity obtained by SSF with Mucor sp. 3P using different algal substrates.

\begin{tabular}{|c|c|c|c|}
\hline Substrate & $\begin{array}{l}\text { Culture media used } \\
\text { for moisture } \\
\text { adjustment }\end{array}$ & $\begin{array}{l}\text { Fucosidase activity } \\
\qquad\left(\mathrm{U} \mathrm{mL}^{-1}\right)\end{array}$ & $\begin{array}{l}\text { Fermentation } \\
\text { time }(\mathrm{h})\end{array}$ \\
\hline \multirow[t]{2}{*}{ Untreated alga - UA } & Water & $6.78 \pm 1.21$ & 120 \\
\hline & Autohydrolyzed liquor & $1.16 \pm 0.23$ & 72 \\
\hline \multirow{2}{*}{$\begin{array}{l}\text { Non-isothermal } \\
\text { autohydrolyzed } \\
\text { alga - NAA }\end{array}$} & Water & $2.94 \pm 0.59$ & 120 \\
\hline & Autohydrolyzed liquor & $3.33 \pm 0.31$ & 120 \\
\hline \multirow{2}{*}{$\begin{array}{l}\text { Non-isothermal } \\
\text { autohydrolyzed } \\
\text { alga supported on } \\
\text { synthetic fiber - } \\
\text { SAA }\end{array}$} & Water & $6.37 \pm 0.11$ & 120 \\
\hline & Autohydrolyzed liquor & $10.75 \pm 1.06$ & 48 \\
\hline
\end{tabular}

artificial substrate $p$-nitrophenyl $\alpha$-L-fucoside (Table 2). Among these, the algal substrate supported on synthetic fiber provided the best results; and on the contrary to the factors affecting fucoidanase production, the addition of the autohydrolysis liquor instead of water to the substrate media enhanced the enzymatic titles (from 6.37 to $10.75 \mathrm{U} \mathrm{mL}^{-1}$ ) and the productivity. Yamamoto et al. (1986) investigated the effects of different carbon sources on $\alpha$-L-fucoside production
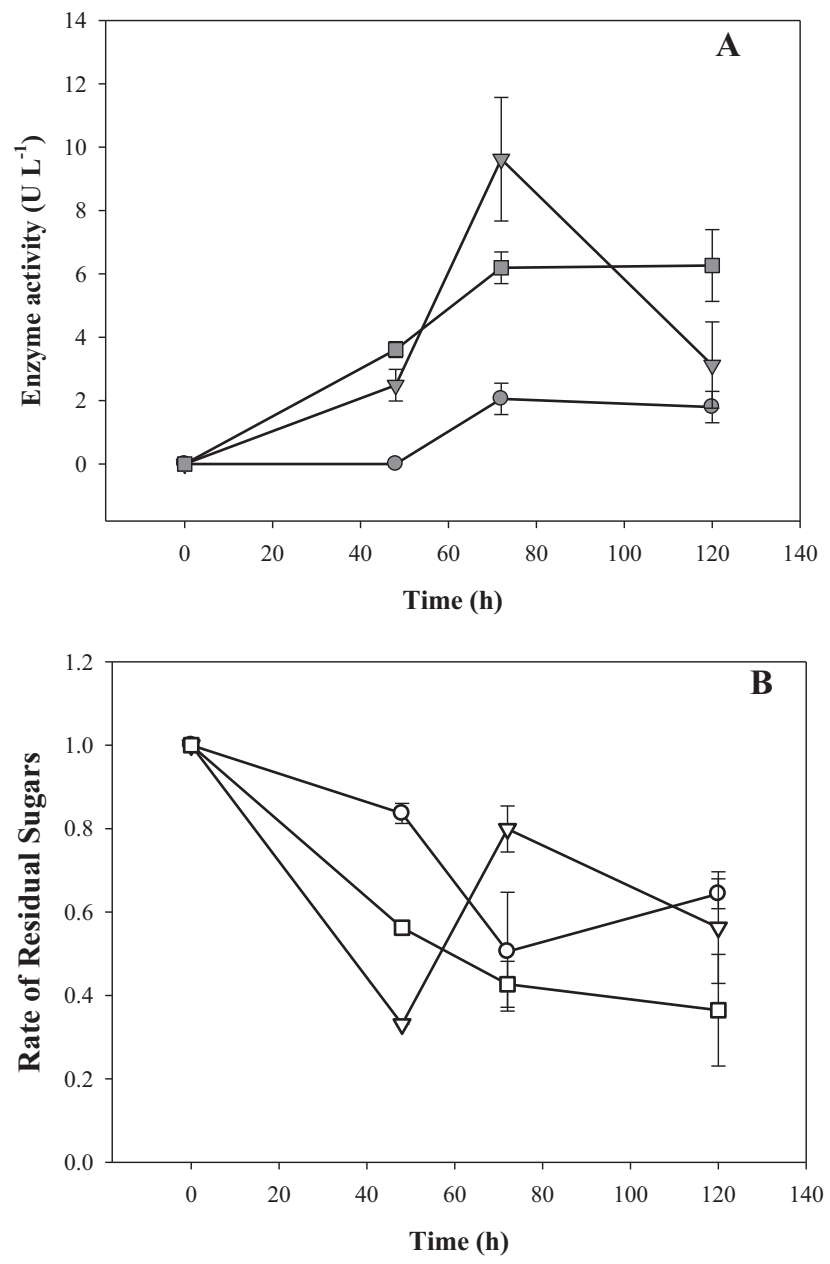

Fig. 5 - Fucoidanase activity (A) and solubilized total sugars (B) in the scale-up experiments of solid-state fermentation with Mucor sp. 3P: (๑○) untreated alga (UA); $(\nabla \nabla)$ non-isothermal autohydrolyzed alga (NAA); $(\square \square)$ non-isothermal autohydrolyzed alga on synthetic fiber cubes (SAA). by Fusarium oxysporum and, among several tested monosaccharides, only L-fucose and $\mathrm{D}$-arabinose caused the production of $\alpha$-L-fucoside with titles of 8 and $1.5 \mathrm{U} \mathrm{mL}^{-1}$, respectively.

\section{Conclusions}

Different algal substrates were evaluated as natural sources for the production of fucoidanase enzymes by solid-state fermentation with fungi. The fucoidanase production was mainly affected by the mixture conditions of the fermentation process, and Mucor sp. 3P strain showed ability to growth and degrade both algal substrates processed by microwave or autohydrolysis. Additionally, the agitation of the system in the rotational drum bioreactor showed a positive effect on the enzyme production when compared to the static experiments. The scale-up assays revealed the importance of controlling the moisture content of the solid substrate, and were able to improve the results obtained at minor scale. To the best of our knowledge, this is the first study on the application of algae as substrate in SSF to produce metabolites of biological interest.

\section{Acknowledgement}

The author Rosa M. Rodríguez-Jasso thanks the Mexican Science and Technology Council (CONACYT, Mexico) for PhD fellowship support (CONACYT 206607/230415).

\section{References}

Aguilar, C.N., Gutiérrez-Sánchez, G., Prado-Barragán, L.A., Rodríguez-Herrera, R., Martínez-Hernandez, J.L., Contreras-Esquivel, J.C., 2008. Perspectives of solid state fermentation for production of food enzymes. Am. J. Biochem. Biotechnol. 4, 354-366.

Alexeeva, Y.V., Ivanova, E.P., Bakunina, I.Y., Zvaygintseva, T.N., Mikhailov, V.V., 2002. Optimization of glycosidases production by Pseudoalteromonas issachenkonii KMM 3549. Lett. Appl. Microbiol. 35, 343-346.

Bakunina, I.Y., Shevchenko, L.S., Nedashkovskaya, O.I., Shevchenko, N.M., Alekseeva, S.A., Mikhailov, V.V., Zvyagintseva, T.N., 2000. Screening of marine bacteria for fucoidanases. Microbiology 69, 303-308.

Berteau, O., Mulloy, B., 2003. Sulfated fucans, fresh perspectives: structures, functions, and biological properties of sulfated fucans and an overview of enzymes active toward this class of polysaccharide. Glycobiology 13, 29R-40R.

Burtseva, Y.V., Verigina, N.S., Sova, V.V., Pivkin, M.V., Zvyagintseva, T.N., 2003. Filamentous marine fungi as 
producers of O-glycosylhydrolases: $\beta$-1,3-glucanase from Chaetomium indicum. Mar. Biotechnol. 5, 349-359.

Burtseva, Y.V., Kusaikin, M.I., Sova, V.V., Shevchenko, N.M., Skobun, A.S., Zvyagintseva, T.N., 2000. Distribution of fucoidan hydrolases and some glycosidases among marine invertebrates. Russ. J. Mar. Biol. 26, 453-456.

Descamps, V., Colin, S., Lahaye, M., Jam, M., Richard, C., Potin, P., Barbeyron, T., Yvin, J.-C., Kloareg, B., 2006. Isolation and culture of a marine bacterium degrading the sulfated fucans from marine brown algae. Mar. Biotechnol. 8, 27-39.

Durand, A., 2003. Bioreactors designs for solid state fermentation. Biochem. Eng. J. 13, 113-125.

Furukawa, S., Fujikawa, T., Koga, D., Ide, A., 1992. Purification and some properties of exo-type fucoidanases from Vibrio sp. N-5. Biosci. Biotechnol. Biochem. 56, 1829-1834.

Giordano, A., Andreotti, G., Tramice, A., Trincone, A., 2006. Marine glycosyl hydrolases in the hydrolysis and synthesis of oligosaccharides. Biotechnol. J. 1, 511-530.

Grimm, L.H., Kelly, S., Hengstler, J., Göbel, A., Krull, R., Hempel, D.C., 2004. Kinetic studies on the aggregation of Aspergillus niger conidia. Biotechnol. Bioeng. 87, 213-218.

Hamidi-Esfahani, Z., Shojaosadati, S.A., Rinzema, A., 2004. Modelling of simultaneous effect of moisture and temperature on A. niger growth in solid-state fermentation. Biochem. Eng. J. 21, 265-272.

Hill, T.W., Kafer, E., 2001. Improved protocols for Aspergillus minimal medium: trace element and minimal medium salt stock solutions. Fungal Genet. Newsl. 48, 20-21.

Holtkamp, A.D., Kelly, S., Ulber, R., Lang, S., 2009. Fucoidans and fucoidanases - focus on techniques for molecular structure elucidation and modification of marine polysaccharides. Appl. Microbiol. Biotechnol. 82, 1-11.

Ivanova, E.P., Bakunina, I.Y., Sawabe, T., Hayashi, K., Alexeeva, Y.V., Zhukova, N.V., Nicolau, D.V., Zvaygintseva, T.N., Mikhailov, V.V., 2002. Two species of culturable bacteria associated with degradation of brown algae Fucus evanescens. Microb. Ecol. 43, 242-249.

Loera, O., Viniegra-González, G., 1998. Identification of growth phenotypes in Aspergillus niger pectinase over-producing mutants using image analysis procedures. Biotechnol. Tech. $12,801-804$.

Ludwig, T.G., Goldberg, H.J.V., 1956. The anthrone method for the determination of carbohydrates in foods and in oral rinsing. J. Dent. Res. 35, 90-94.

Machado, E.M.S., Rodriguez-Jasso, R.M., Teixeira, J.A., Mussatto, S.I., 2012. Growth of fungal strains on coffee industry residues with removal of polyphenolic compounds. Biochem. Eng. J. 60, 87-90.

Marin-Cervantes, M.C., Matsumoto, Y., Ramírez-Coutiño, L., Rocha-Pino, Z., Viniegra, G., Shirai, K., 2008. Effect of moisture content in polyurethane foams as support for solid-substrate fermentation of Lecanicillium lecanii on the production profiles of chitinases. Process Biochem. 43, 24-32.

Martins, S., Mussatto, S.I., Martínez-Avila, G., Montañez-Saenz, J., Aguilar, C.N., Teixeira, J.A., 2011. Bioactive phenolic compounds: production and extraction by solid-state fermentation. A review. Biotechnol. Adv. 29, 365-373.

Miller, G.J., 1959. Use of dinitrosalicylic acid reagent for determination of reducing sugar. Anal. Chem. 31, 426-428.

Mussatto, S.I., Ballesteros, L.F., Martins, S., Teixeira, J.A., 2012. Use of agro-industrial wastes in solid-state fermentation processes. In: Show, K.-Y., Guo, X. (Eds.), Industrial Waste. InTech - Open Access Publisher, Rijeka, Croatia, pp. 121-140.

Mussatto, S.I., Aguilar, C.N., Rodrigues, L.R., Teixeira, J.A., 2009. Colonization of Aspergillus japonicus on synthetic materials and application to the production of fructooligosaccharides. Carbohydr. Res. 344, 795-800.

Mussatto, S.I., Roberto, I.C., 2004. Alternatives for detoxification of diluted-acid lignocellulosic hydrolyzates for use in fermentative processes - a review. Bioresour. Technol. 93, 1-10.

Robledo, A., Aguilera-Carbó, A., Rodriguez, R., Martinez, J.L., Garza, Y., Aguilar, C.N., 2008. Ellagic acid production by Aspergillus niger in solid state fermentation of pomegranate residues. J. Ind. Microbiol. Biotechnol. 35, 507-513.

Rodriguez-Jasso, R.M., Mussatto, S.I., Pastrana, L., Aguilar, C.N., Teixeira, J.A., 2013. Extraction of sulfated polysaccharides by autohydrolysis of brown seaweed Fucus vesiculosus. J. Appl. Phycol. 25, 31-39.

Rodriguez-Jasso, R.M., Mussatto, S.I., Pastrana, L., Aguilar, C.N., Teixeira, J.A., 2011. Microwave-assisted extraction of sulfated polysaccharides (fucoidan) from brown seaweed. Carbohydr. Polym. 86, 1137-1144.

Rodriguez-Jasso, R.M., Mussatto, S.I., Pastrana, L., Aguilar, C.N., Teixeira, J.A., 2010. Fucoidan-degrading fungal strains: screening, morphometric evaluation, and influence of medium composition. Appl. Biochem. Biotechnol. 162, 2177-2188.

Singhania, R.R., Patel, A.K., Soccol, C.R., Pandey, A., 2009. Recent advances in solid-state fermentation. Biochem. Eng. J. 44, 13-18.

Vonshak, A., Maske, H., 1982. Algae: growth techniques and biomass production. In: Coombs, J., Hall, D.O. (Eds.), Techniques in Bioproductivity and Photosynthesis. Pergamon Press, Oxford, pp. 66-77.

Wu, Q., Zhang, M., Wu, K., Liu, B., Cai, J., Pan, R., 2011. Purification and characteristics of fucoidanase obtained from Dendryphiella arenaria TM$_{94}$. J. Appl. Phycol. 23, 197-203.

Yamamoto, K., Tsuji, Y., Kumagai, H., Tochikura, T., 1986. Induction and purification of $\alpha$-L-fucosidase from Fusarium oxysporum. Agric. Biol. Chem. 50, 1689-1695. 